\title{
EFFECT OF TWO DIFFERENT FORMS OF THREE-POINT LINE ON GAME ACTIONS IN GIRLS' MINI-BASKETBALL
}

\author{
José L. ARIAS*, Francisco M. ARGUDO* \& José I. ALONSO** \\ *Department of Physical Education, Sport and Human Movement, Autonomous University of \\ Madrid, Madrid, Spain \\ **Department of Plastic, Musical and Dynamic Expression, University of Murcia, Murcia, \\ Spain
}

\begin{abstract}
The aim of this study was to compare two different designs of the three-point line to analyze which one allows for a higher frequency of motor actions that, according to the bibliography, should be strengthened when including a three-point line in youth basketball. In the first of two championships, female mini-basketball players $(n=67)$ played with a three-point line delimited by the free throw lane, while during the second one, they played with a rectangular three-point line. Four observers were trained. The reliability reached values between .90 and .98 . The Mann-Whitney $U$ Test was used to determine if there were significant differences among the averages of the compared variable. When participants used the three-point line delimited by the free throw lane, there were increases in the percentage of ball possessions that ended in a shot $(U=1280785, Z=-3.827, p=.000)$, that ended in shots from zones $A$ $(U=1286321, Z=-3.531, p=.000)$ and $C(U=1356614, Z=-2.182, p=.029)$, in standard shots $(U=1294771, Z=-3.269, p=.001)$, in hook shots $(U=1358526, Z=-$ $3.176, p=.001)$, in three-point shot attempts $(U=1314902, Z=-6.600, p=.000)$, and in successful three-point shots $(U=1355201, Z=-3.888, p=.000)$. This study confirms the necessity of consulting with analysts before introducing and modifying a rule in sport.
\end{abstract}

Key words: Basketball; Rule modification; Shot; Youth sport.

\section{INTRODUCTION}

Jay Archer created mini-basketball as an adaptation of basketball for children's characteristics and needs so that they could play and enjoy it in accordance with their capabilities. In Spain, according to regulations by the Spanish Basketball Federation (SBF), mini-basketball is played between two teams of five players each, who are eleven years of age and under. Six periods of eight minutes are played on a court measuring $28 \times 15$ meter in which there are two basketball hoops at a height of 2.60 meters. According to Piñar et al. (2002/2003), Piñar (2005), and Arias et al. (2009), ball possessions that end in shot attempts, successful shots, lay-ups, hook shots, shots attempts from distances greater than four meters or from positions outside the free throw lane ("lane") are scarcely carried out in minibasketball. Additionally, since there is no three-point line, players cannot score three-point baskets. This, and the fact that players attempt few shots outside of four meters, limits their play and enjoyment in accordance with their capabilities. The SBF proposed a three-point 
line delimited by a rectangular area similar to a goal area in soccer. With this new rule in mind, some organizations (counties basketball federations and the counties governments) in each Spanish autonomous community opted to use a three-point line delimited by the rectangular area, while others opted to use the line that delimits the free throw lane as a threepoint line (see Figure 1). However, none of the organizations conducted studies beforehand to assess the impact that either of these two lines can have on the game actions of minibasketball players during the game. From reference studies, the three-point line should facilitate the development of situations that end in a shot, that strengthen the shot from outside of the free throw lane, lay-ups, and hook shots, and that increase the number and effectiveness of three-point shots (D’Silva et al., 1988; Andreasen, 1990; Adams, 1991; Piñar et al., 2002/2003; Piñar, 2005; Arias et al., 2008, 2009). However, information does not exist about what type of three-point line facilitates these motor actions to the greatest extent.

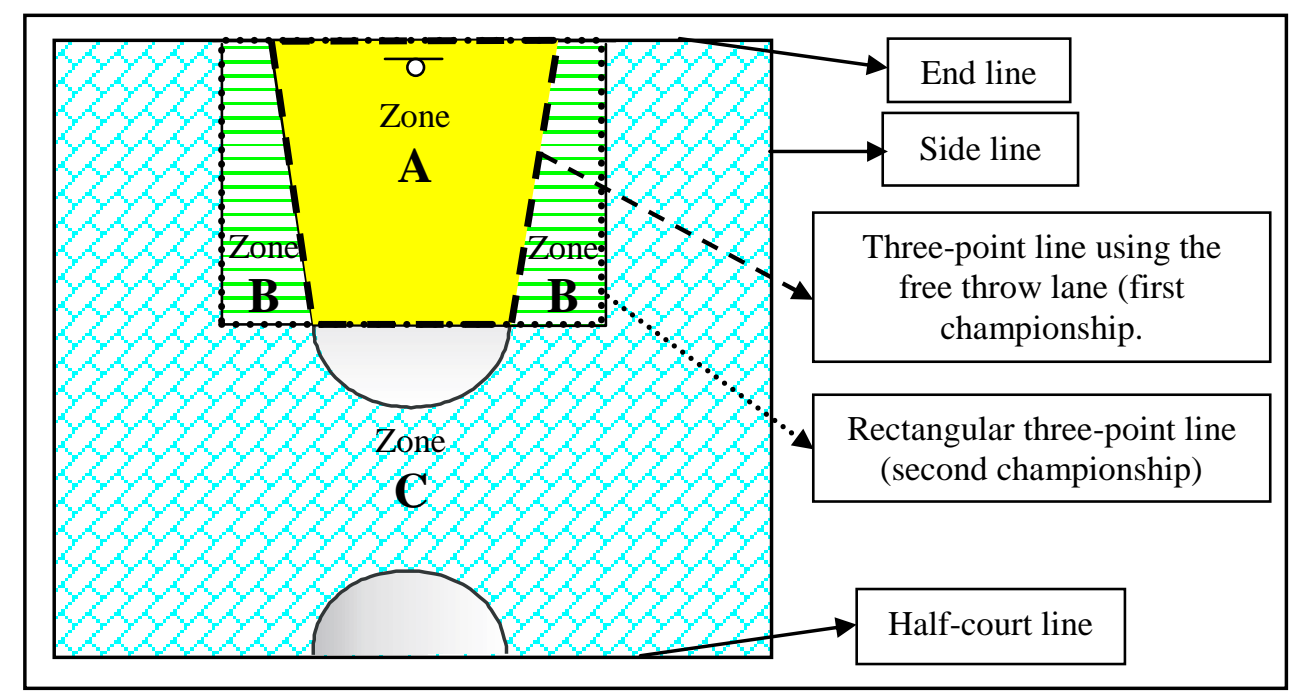

\section{FIGURE 1: THREE-POINT LINE USING THE FREE THROW LANE AND RECTANGULAR THREE-POINT LINE.}

The motor praxeology establishes that rules designate the requisites for the development of the game actions, which determine the internal logic of the sport that they regulate (Parlebas, 2001). The prescriptions set forth by the regulations define the game actions, given that the regulations establish four types of relationships that cause the motor action to emerge (Parlebas, 2001) namely; (a) between participants (b) between the participant and the game space (c) between the participant and the objects and/or tools that influence the contest, and (d) the mode in which the participant must adjust to the game tempo. When changing the three-point line, the game space is modified and it may also change the game actions. This requires that studies be conducted that are focused on the analysis of game actions. The game action is the fundamental aspect that is directly affected by the changes, and it is expressed through observable, objective motor behaviours. 
From a pedagogical perspective, rules are a didactical resource and are established to cause the desired adaptation in individuals (Rink, 1993; Pellett et al., 1994; Pellett \& Lox, 1998). The modification of the practice conditions has specific objectives namely to generate a simplified approach that is suitable for the level of the children, to allow much opportunity for practice, to be able to execute it successfully, and to increase the enjoyment (Pellett et al., 1994; Brown et al., 2000; Prusak \& Darst, 2000). According to Prusak and Darst (2000), small adjustments can make a tremendous impact in the learning environment. However, there are few scientific studies that analyze the rules and their modification as pedagogical variables (Weidner, 1998).

Previous studies justify the need to assess whether the objective for which a rule is modified is actually fulfilled before the objective is definitively established (Nevill et al., 2008). In basketball, D'Silva et al. (1988) analyzed the impact of the inclusion of a three-point line on the shot in the National Championship at Calcutta. The results demonstrated that the standard shot was the most suitable for making a three-point field goal and increased the number of successful three-point field goals by the shortest players, although the shots that were close to the hoop were still the most predominant. Romanowich et al. (2007) studied the effect of first bringing the three-point line nearer the basket and later distancing the line in the National Basketball Association (NBA). The conclusions indicated that when bringing the three-point line nearer to the hoop, the relative frequencies of shot attempts and successful shots were increased. On the other hand, when they again distanced the line, the relative frequency of attempts, but not successful shots, decreased. In youth basketball, Andreasen (1990) analyzed the effect of the inclusion of a three-point line on seven teams of 15 to 16 year-old players. The results demonstrated an increase in man-on-man defence, which allows for creating spaces and facilitating the shot from inside positions. The coaches proposed situating the three-point line nearer to the basket, but they did not specify the distance. Adams (1991) evaluated the three-point shots from the basketball team at Mountain View High School in relation to various game statistics. The results indicated that the three-point line seemed to cause the defensive players to organize themselves around this line and increased the use of man-on-man defence.

In mini-basketball, Piñar et al. (2002) found that the majority of shots were taken from inside the free throw lane $(81 \%)$, after analyzing the positions and distances during the regular season. From their results, they proposed a three-point line that was similar to the adult line and that was four meters from the hoop in order to increase the number of shots taken outside of the free throw lane, the free spaces close to the hoop, and the variability of the shots taken. As far as we know, only two studies about modifications in the mini-basketball regulations have been done in the context of competition. Piñar (2005) modified a series of rules during two championships, among which was the inclusion of a three-point line four meters from the hoop which was similar to the adult three-point line. The purpose of Piñar's study was to increase the number of ball possessions that end in a shot, the shots from outside of the free throw lane, the lay-ups and hook shots, and to offer the opportunity to try to achieve threepoint shots. The results demonstrated a $17 \%$ increase in the number of successful shots, a $3.5 \%$ increase in the standard and hook shots, a $13.7 \%$ increase in ball possessions in which the ball was shot from outside the free throw lane and a $9.6 \%$ increase in ball possessions in which the ball was shot from a distance greater than four meters. However, as various modifications were included (size of the court, free throw line, player participation time, and 
number of players taking part), it could not be determined whether the results were a consequence of the inclusion of the three-point line only or if other modifications affected these results. Arias et al. (2009) compared the two three-point lines that are studied in the present study during two championships. The results demonstrated that there was an increase in points scored, number of players taking part in the ball possession, number of passes, and number of 1-on-1 situations when players utilized the three-point line delimited by the free throw lane. Although these variables would appear to be unaffected by the modification of the three-point line, the results were due to the fact that the modification affects the game dynamics. This is an effect of the interaction between the rule change and the game actions (Parlebas, 2001). However, this study (Arias et al., 2009) does not evaluate which of the two models should facilitate the development of situations recommended in the bibliography for the three-point line: (a) those that end in a shot attempt, (b) those that strengthen the shot from outside of the free throw lane, (c) those that make use of the lay-up and hook shot, and (d) those that increase the number and effectiveness of three-point shots.

The aim of this study was to compare the three-point line delimited by the free throw lane and the three-point line delimited by a rectangular area to analyze which of the two three-point line designs allows for a higher frequency of ball possessions that end in a shot, that end in a shot attempt from outside of the free throw lane, that increase the number of lay-up and hook shot attempts, and that attain a higher number and effectiveness of three-point shots. The hypothesis is that with the three-point line delimited by the free throw lane, there could be a greater frequency of shot attempts from outside the free throw lane as well as three-point shot attempts and successful three-point shots, as the free throw lane is smaller than the rectangular area. We did not hypothesize about which three-point line would obtain a greater frequency of ball possessions that end in a shot attempt and with which there would be more lay-up and hook shot attempts, as there are no previous studies that have analyzed these relationships.

\section{METHOD}

\section{Participants}

The participants of the study consisted of female players $(\mathrm{N}=67)$ with an average age of 10.39 years $(\mathrm{SD}=0.67)$ from six mini-basketball teams that played in an official competition within their province, during the 2006-2007 season. The players had been competing in their sport for $2.11(\mathrm{SD}=0.77)$ years, and they played $3.5(\mathrm{SD}=0.55)$ days per week for a total of 5.33 $(\mathrm{SD}=1.35)$ hours. The players participated in two championships. In each championship there was a total of nine games, with each team competing in three games. The sample consisted of 3,311 ball possessions, 1,642 ball possessions from the first championship and 1,669 from the second one. The sample was selected through a total sampling of the actions that took place (Anguera, 2003). The University's Institutional Ethics Review Board approved the study (CEI 22-540). Before carrying out the empirical part of the study, the players' parents and coaches provided informed consent to participate in this study. 


\section{Experimental set-up}

Ten mini-basketball teams were invited to compete in two championships. From these 10 teams, six were selected to participate, because they had not previously practiced or competed with a three-point line. Neither the coaches nor the players knew the goal of the study. The coaches were informed that: (a) they would play in two championships of nine games each (three games per team), (b) there would be 30 days between championships, and (c) in each championship players would use a different three-point line. Further, coaches were asked to: (a) train with the three-point line delimited by the free throw lane (see Figure 1) for four weeks before the first championship, (b) train with the three-point line delimited by the rectangular area (see Figure 1) for four weeks before the second championship, (c) hold a minimum of three one-hour practices each week, (d) remind players at the beginning of each practice that the shot attempts from behind the three-point line are worth three points, (e) continue working on the same content in each practice session and not include specific exercises to work on three-point shots, and (f) assure that the same players participated in the two championships. The principal researcher informed the coaches about the characteristics of the two championships (see Table 1) two months before the first championship. Successful shots outside zone A were worth three points in the first championship and shots outside zones $\mathrm{A}$ and $\mathrm{B}$ were worth three points in the second championship. The lane consists of a trapezoid with a 6 meter base that runs along the baseline, 3.6 meter free throw line at the opposite end and the sides measured 5.80 meters. The rectangular area measured 8 meters long by 4 meters wide.

\section{TABLE 1: CHARACTERISTICS OF THE CHAMPIONSHIPS}

\begin{tabular}{|ll|}
\hline \multicolumn{1}{|c|}{ Aspect } & \multicolumn{1}{c|}{ Characteristics } \\
\hline & - Teams were divided into two groups of three teams each. Within each \\
& group, all teams played each other and a classification was determined. \\
& Finally, teams played against the other group according to their \\
System of competition & classification (1st vs. 1st, 2nd vs. 2nd, 3rd vs. 3rd). \\
& - The match-ups were the same in the two championships. \\
& - Man-on-man defense was required. \\
& - This took place in one day, from 9AM to 6PM. \\
& - The same players had to participate in the two championships. \\
& - Teams were composed of 8-12 players. \\
Participating players & - Five players on the court at a time. \\
& - Between 9 and 11 years. \\
Age of players & - Six periods of 8 minutes. \\
Duration of games & - One minute between periods. \\
Rest time per game & - Five minutes between the 3rd and 4th periods. \\
Rest time between games & - Ten minutes. \\
Court dimensions & - 28 $\times 15$ m. \\
Court placement & - Within the same gymnasium. \\
Game ball size & - Weight: $470-500$ g., Circumference: $69-71 \mathrm{~cm}$. \\
Basket height & $-2.60 \mathrm{~m}$. \\
Referees & - Four. \\
External factors & - Public in the stands.
\end{tabular}




\section{Design and procedure}

Observational methodology, which is accepted as an empirical methodology for the performance sciences (Anguera \& Blanco, 2003), was used through a follow-up, idiographic, multidimensional design type (Anguera, 2003).

Preparation of the observation instrument. We used a category system as the observation instrument (Anguera \& Blanco, 2003). The process of elaborating the category system consisted of three steps. In the first step, an expert group of coaches and the researchers determined the variables to be studied following the empirical inductive strategy affected by the lack of theoretical constructs and the multidimensional character of the action (Gorospe et al., 2005). In the second step, an operational definition of each variable and its categories was distinguished. This system took shape during the observer training phase. The category system was exhaustive and mutually exclusive. The categories were coded using a numeric system to facilitate its register. The category system was formed by the following variables and categories:

1. Manner of ending the ball possession: the action with which players stopped controlling the ball was registered. Adapting the categories cited by Piñar (2005) and the conditions of the shot clock, the following categories were established: (a) shot, (b) turnover, (c) steals and interceptions, (d) defensive error and (e) referee's decision.

2. Shooting zone: the area where shots were executed in each ball possession was registered. From Piñar (2005), and Arias et al. (2009), the following categories were established (see Figure 1): (a) zone A, (b) zone B, and (c) zone C.

3. Type of shot: the shooting technique used in each ball possession was registered. From Piñar (2005), the following categories were established: (a) standard shot, (b) lay-up, and (c) hook shot.

4. Three-point shooting performance: the number of three-point shot attempts and the number of successful three-point shots were registered in each ball possession. The following categories were established: (a) number of three-point shot attempts and (b) number of successful three-point shots.

Filming. Nine games were recorded within each championship with two video cameras (JVC, Everio Full HD-GZ-HD7), each one situated transversely to one of the two mini-basketball courts. The cameras were placed at a height of five meters. The recording focused on the player with the ball and the basketball hoop, while also including as much of the rest of the court as possible in the image. The three-point lines of each court were measured and put into place with $200 \mathrm{~m}$. of adhesive tape the night before each championship.

Preparation of the register instrument, the training manual and the instruction manual for the observers. The register instrument (Anguera \& Blanco, 2003) was created from the adaptation of a Microsoft Excel 2003 worksheet (Microsoft Corporation, USA) to which a tool to capture and process the videos was added (Virtual Dub, v. 1.7.0.). This instrument allowed the observers to register the number corresponding to each category in the Excel 
sheet while likewise viewing the recording at a speed of 25 frames per second. This instrument fostered correct transcription of the data (Castellano et al., 2008). To guide the observers' training process, we created a training manual that described: (a) the objective of the training process; (b) basic concepts of observational methodology; (c) the stages to follow in the training process; and (d) the structure of the training sessions. An instruction manual for the observers was also created, which consisted of: (a) the category system; (b) the coding of the categories; and (c) the process for completing the register instrument.

Observer training and obtaining the register's reliability. Four observers were trained for at least 40 hours, following the training and coaching stages suggested by Anguera (2003). Observers' performance was evaluated through reliability when compared to an expert observer. The expert observer had more than 100 hours logged in the registering of game actions as well as intra-observer reliability values between .98 and 1. To measure the reliability, the observers and the expert individually observed an 18-minute fragment of an additional game. The data they recorded were compared and the reliability was calculated utilizing the Kappa's concordance coefficient, reaching values between .90 and .98 .

Data collection. Data were collected via systematic registration (Anguera \& Blanco, 2003). Data were registered through observation of the recorded games. Each ball possession was considered a unit of analysis. To increase the observation reliability, the protocol of observing each ball possession four times at real time was used. Each time one of the criteria to analyze was focused on. Once the corresponding category to each criterion was located, the observers again viewed the ball possession at 25 frames per second as many times as necessary to identify whether it fulfilled the key aspects that determined each category. In each observation of a ball possession, observers registered the numerical code corresponding to each criterion on which an observation was focused. Once this process was finished, the protocol was repeated with all the ball possessions.

\section{Statistical analysis}

Data were collected through a register instrument to capture, file, and later treat them statistically with a statistical package (SPSS, v.13.0. for Windows). We performed descriptive analyses for each variable, calculating frequencies and percentages. The normality of the data through the Kolmogorov-Smirnov test was examined, and according to this test the data were non-parametric. The Mann-Whitney U Test was used to determine if there were significant differences among the averages of the compared variable according to the two three-point line designs. Significance was set at $p<.05$.

\section{RESULTS}

As shown in Table 2, statistically significant differences between the two championships were found for ball possessions that ended in a shot $(U=1280785, Z=-3.827, p=.000)$ and those that ended with a defensive error $(U=1339674.5, Z=-2.416, p=.016)$. A higher percentage of ball possessions ended in shots during the first championship (62.9\% vs. $56.3 \%$ ), while a higher percentage of ball possessions ended with a defensive error during the second championship (6.5\% vs. $8.7 \%$ ). Statistically significant differences were not found for the ball possessions that ended in a turnover $(U=1356561, Z=-.715, p=.474)$, a steal or 
interception $(\mathrm{U}=1342866.5, \mathrm{Z}=-1.851, \mathrm{p}=.064)$, or a referee's decision $(\mathrm{U}=1352430, \mathrm{Z}=$ $-2.851, \mathrm{p}=.061)$. Statistically significant differences were found between the two championships for ball possessions in which there was a shot attempt from zones A (U = $1286321, \mathrm{Z}=-3.531, \mathrm{p}=.000)$ and $\mathrm{C}(\mathrm{U}=1356614, \mathrm{Z}=-2.182, \mathrm{p}=.029)$. During the first championship, a higher percentage of ball possessions ended with a shot attempt from zones A $(56.4 \%$ vs. $50.3 \%)$ and C (2.3\% vs. $1.3 \%)$. No statistically significant differences were found for shot attempts from zone $B(U=1361329, Z=-.900, p=.368)$. Statistically significant differences were found between the two championships for ball possessions in which there was a standard shot attempt $(\mathrm{U}=1294771, \mathrm{Z}=-3.269, \mathrm{p}=.001)$ or a hook shot attempt $(\mathrm{U}=1358526, \mathrm{Z}=-3.176, \mathrm{p}=.001)$. During the first championship, there was a higher percentage of ball possessions in which a standard shot $(40.5 \%$ vs. $35 \%)$ or a hook shot $(1 \%$ vs. $0.2 \%)$ was attempted. There were statistically significant differences between the two championships for the ball possessions in which there was a three-point field goal attempt $(\mathrm{U}=1314902, \mathrm{Z}=-6.600, \mathrm{p}=.000)$ as well as a successful three-point field goal (U $=1355201, \mathrm{Z}=-3.888, \mathrm{p}=.000)$. In the first championship, there was a higher percentage of ball possessions in which there was a three-point field goal attempt $(6.4 \%$ vs. $1.3 \%)$ and a successful three-point field goal $(1.2 \%$ vs. $0.1 \%)$.

\section{TABLE 2: FREQUENCIES, PERCENTAGES AND SIGNIFICANT DIFFERENCES OF THE MEANS OF THE COMPARED VARIABLES ACCORDING TO THE TWO THREE-POINT LINE DESIGN}

\begin{tabular}{|c|c|c|c|c|c|}
\hline \multirow{3}{*}{ Variables } & \multirow{3}{*}{ Categories } & \multicolumn{4}{|c|}{ Championship } \\
\hline & & \multicolumn{2}{|c|}{$\begin{array}{c}\text { First: free throw } \\
\text { lane }\end{array}$} & \multicolumn{2}{|c|}{$\begin{array}{c}\text { Second: } \\
\text { rectangular area }\end{array}$} \\
\hline & & $\bar{n}$ & $\%$ & $\mathrm{n}$ & $\%$ \\
\hline \multirow{5}{*}{$\begin{array}{l}\text { Manner of ending } \\
\text { the ball possession }\end{array}$} & Shot.*** & 1032 & 62.9 & 941 & 56.3 \\
\hline & Turnover. & 324 & 19.7 & 346 & 20.7 \\
\hline & Steal or interception. & 161 & 9.8 & 196 & 11.8 \\
\hline & Defensive error.** & 107 & 6.5 & 146 & 8.7 \\
\hline & Referee's decision. & 018 & 1.1 & 40 & 2.4 \\
\hline \multirow{3}{*}{ Shooting zone } & Zone A.*** & 926 & 56.4 & 838 & 50.3 \\
\hline & Zone B. & 069 & 4.2 & 81 & 4.9 \\
\hline & Zone C.* & 037 & 2.3 & 22 & 1.3 \\
\hline \multirow{3}{*}{ Type of shot } & Standard.*** & 665 & 40.5 & 584 & 35 \\
\hline & Lay-up. & 350 & 21.3 & 354 & 21.2 \\
\hline & Hook.*** & 017 & 1 & 3 & 0.2 \\
\hline \multirow{2}{*}{$\begin{array}{l}\text { Three-point shooting } \\
\text { performance }\end{array}$} & Three-point shot attempts. $* * *$ & 106 & 6.4 & 22 & 1.3 \\
\hline & Successful three-point shots. $* * *$ & 020 & 1.2 & 2 & 0.1 \\
\hline
\end{tabular}

Note. $*(p<.05) ; * *(p \leq .01) ; * * *(p \leq .001)$

\section{DISCUSSION}

The aim of this study was to compare the three-point line delimited by the free throw lane and the three-point line delimited by a rectangular area to analyze which of the two three-point line designs allows for a higher frequency of ball possessions that end in a shot, that end in a shot attempt from outside of the free throw lane, that increase the number of lay-up and hook shot attempts, and that attain a higher number and effectiveness of three-point shots. The 
percentage of ball possessions that ended in a shot attempt, in a shot attempt from zone A or $\mathrm{C}$, a standard or hook shot, and both three-point field goal attempts and successful three-point field goals increased when participants used the three-point line delimited by the free throw lane. The frequency of shot attempts from outside the free throw lane and of lay-ups was not different between the two designs that were studied. This demonstrates that the three-point line with which participants played in the first championship better facilitated the playing and enjoyment of these youth participants in accordance with their capabilities (Piñar et al., 2002, 2003; Piñar, 2005; Arias et al., 2009), which, according to the bibliography should foster an increase in the perceived competence (Hassandra et al., 2003), in the fun and enjoyment (MacPhail et al., 2008), and in self-efficacy (Bandura, 1977; Chase et al., 1994). The predominance of these motives should allow for greater adherence to mini-basketball, specifically, and to sport participation, in general (Hassandra et al., 2003; Weiss \& Williams, 2004; Xiang et al., 2004).

The primary goal of a mini-basketball game is to score or make baskets, as with other team ball sports. This does not mean that the other motor skills are not necessary, but rather that the other motor skills are done to facilitate making baskets. Therefore, the shot should be the motor skill that finishes most ball possessions in mini-basketball (Piñar, 2005). In the first championship, $6.6 \%$ more ball possessions ended in a shot. This situation is ideal in minibasketball, because the shot is one of the most motivating motor actions (Prusak, 1997; Vollmer \& Bourret, 2000; Palao et al., 2008). The data with regard to ball possessions that end in shots from the current study were higher than those found by Piñar (2005), in girls' mini-basketball. Piñar (2005) found that $24.1 \%$ of the possessions in 5-on-5 ended in a shot compared to $29.1 \%$ in 3 -on-3. Also, $2.2 \%$ more ball possessions ended with a defensive error (violation and personal foul) in the second championship. In general, 5.2\% more ball possessions ended in a negative action (turnover, steal/interception, or defensive error) in the second championship. The players ended more possessions with errors in the second championship, and this could be due to the inclusion of a three-point line that is not welladapted to the development of the players, as inferred in the bibliography (Piñar, 2005; Arias et al., 2009). This may be due to the fact that the rectangular three-point line is so far from the hoop, and the organization that teams adopt in offense and defence in relation to the threepoint line seems to produce an adverse effect on the actions of the players. Nonetheless, this result requires future study to discover whether the inclusion of a three-point line affects the spatial perception of offense and defence.

According to Miller and Bartlett (1996) and Liu and Burton (1999), shooting distance is the first factor that affects shooting accuracy and form. The analysis of the shooting distance contributes useful information for improving youth development. In accordance with Liu and Burton (1999), it is necessary to know the critical distance to the hoop where the number of shots, the precision, and the form are affected or impaired. The number of shot attempts from zone A was higher in the first championship. This could be due to a placement of the defence such that it permitted more spaces inside the free throw lane (D'Silva et al., 1988; Andreasen, 1990; Adams, 1991; Piñar, 2005; Arias et al., 2009). D'Silva et al. (1988) argue that in spite of the increase in the three-point shots, the shots closer to the hoop still predominated after the inclusion of the three-point line. The shots that are close to the hoop predominate because of their greater effectiveness in basketball (Tsitskaris et al., 2002; Tavares \& Gomes, 2003; Mexas et al., 2005). The number of shots attempted from outside the free throw lane was 
similar in the two championships. The number of shot attempts was similar from zone B and greater from zone $\mathrm{C}$ in the first championship. This result could be surprising because the value of the shots from zones $\mathrm{B}$ and $\mathrm{C}$ in the first championship was 3 points and in the second championship only the shots from zone $\mathrm{C}$ had a value of 3 points; thus, it seems logical that there should have been an increase in the number of shots from zone B in the first championship since it was closer to the hoop. From the results of a study by Adams (1991), it was found that defenders seemed to organize themselves around this line. This result seems to be related to the placement of the offense and defence in zone B in the first championship, which would limit the shots from this zone. In the second championship, the offensive and defensive organization in zone $\mathrm{C}$ would have predominated, which would have reduced the number of shots from this zone. However, this should be tested in future studies by analyzing the placement of the offense and defence and asking those on offense about their shot decisions. Piñar et al. (2002) observed that $81 \%$ of shots were attempted from inside the restricted area when playing without a three-point line in boys' mini-basketball. Piñar et al. (2003) likewise obtained a value of $69.5 \%$ without a three-point line in boys' mini-basketball. For girls' mini-basketball, Piñar (2005) reported that $71.6 \%$ of shots were attempted from inside the restricted area for the 5-on-5 modality when playing without a three-point line, compared to $54.7 \%$ for the 3-on-3 modality when playing with a three-point line. As confirmed by previous studies when introducing a three-point line, the number of shots attempted from distances greater than the restricted area increase (Piñar, 2005), but in the present study the shot percentages were not as high as reported in the bibliography. This could be due to the series of modifications introduced by Piñar (2005). It seems that it is necessary to analyze other modifications in the regulations in order to increase the number of shots from outside the free throw lane.

Because of its special importance as a specific motor action with which the rest of the actions and tactical resources are completed, and because of its direct relationship with the goal of the game, it is important to know the kind of shots that players attempt (Tsitskaris et al., 2002; Ibáñez et al., 2009). The participants mostly used the standard shot in the first championship. The higher number of standard shots in the first championship was due to the greater number of shot attempts from zones A and C. In zone A, the standard shot increased because the presence of close opponents requires increasing the angle and release height of the ball, and this is achieved with the standard jump shot (Rojas et al., 2000). The shots from zone $\mathrm{C}$ were standard because the increase in the distance with regard to the hoop brings about an increase in the speed of ball release (Elliott, 1992; Miller \& Bartlett, 1996). This causes the players with less strength to increase their horizontal displacement in order to generate the necessary speed to allow the ball to reach the hoop (Elliott, 1992; Miller \& Bartlett, 1996; Liu \& Burton, 1999). D'Silva et al. (1988) also found that the standard shot was the shot that was most utilized for attempting three-point field goals. The hook shot was the other type of shot that was most used in the first championship from zone A. In mini-basketball, the hook shot is suggested for positions that are close to the hoop and with defenders that are very close, since it is used to protect the ball. However, it is not utilized much due to the difficulty that its execution involves (Ibáñez et al., 2009). Piñar (2005), after including the three-point line, found a $3.5 \%$ increase in standard and hook shots. In the present study, the first championship had an increase of $6.3 \%$. The increase in the number of hook shots means that the participants had the opportunity to practice a type of shot that is not used much. The standard shot was the type of shot that was most used, followed by the lay-up and the hook shot in both 
championships. This shot pattern is common in basketball (Tsitskaris et al., 2002; Ibáñez et al., 2009). Ibáñez et al. (2009) analyzed 8,471 shots from the NBA and found that $62.7 \%$ were standard shots, $19.1 \%$ were lay-ups, and $5.9 \%$ were hook shots. Tsitskaris et al. (2002) found that for shots taken in the Green national leagues, $49.2 \%$ were standard shots and $14.4 \%$ were lay-ups. However, working on variability of shot type is necessary in youth basketball (Tsitskaris et al., 2002; Piñar, 2005). Variability fosters the learning of a considerable number of types of shots, which contribute to the development of an adaptable cognitive-motor system in this regard (Memmert \& Roth, 2007). More analytical studies should allow us to know how the type of shot is modified in regard to the increased distance and zone (frontal or lateral) with regard to the hoop in mini-basketball.

In mini-basketball, the study by Arias et al. (2009) analyzes the influence of simply including a three-point line on various motor actions during the game. In addition to this study, there are others that demonstrate the importance of including a three-point line with regard to the practice of motor actions that are better adapted to the capabilities of the players during the game (Piñar, 2005; Arias et al., 2008). Participants made 6.3\% more three-point shot attempts in the first championship. This aspect is especially important as noted by Piñar (2005) and Arias et al. (2009) because an increase in the amount of practice can aid in learning and development. Participants made $1.1 \%$ more three-point shots in the first championship. This coincides with the fact that a greater number of three-point shot attempts allows for more successful three-point shots (Romanowich et al., 2007). Arias et al. (2009) also found that the participants achieved a higher percentage of ball possessions in which they made a successful three-point field goal $(1.1 \%)$ when playing with a three-point line delimited by the free throw lane. Therefore, in the first championship, the possibilities to attempt and score a three-point shot were more suitable for the capacities of the players. This would contribute to the increase in the levels of perceived self-efficacy (Bandura, 1977; Chase et al., 1994), which likewise reflects on motivation (Bandura, 1977; Chase, 2001). Piñar (2005), when including a threepoint line in the 3-on-3 modality that was similar to the adult three-point line but at four meters from the hoop, found that the girls achieved a successful three-point basket in $4 \%$ of the ball possessions, for a total of nine baskets. For male players, this happened in $13.9 \%$ of possessions, which were a total of 36 baskets. In the present study, when playing with the three-point line delimited by the restricted area, players only made three-point baskets in $1.2 \%$ of ball possessions, which comprised 20 baskets. As it is necessary for mini-basketball players to practice shooting from distances greater than that which delimits the restricted area without hurting their precision and form, it is necessary for future studies to assess the optimal distance from the basket to place the three-point line as well as studying other aspects that facilitate successful three-point baskets. Participants took successful three-point shots from zone B $60 \%$ of the time and from zone C $40 \%$ of the time in the first championship. The only two successful three-point shots were attempted from zone $\mathrm{C}$ in the second championship. However, if in this championship, shots from zone B had been worth three points, 17 more would have been made. The reduction in the distance from the basket to the three-point line in the first championship had a favourable effect on the effectiveness of the three-point shot. Given that zone B is between 2.87 and 5.65 meters from the basket, it seems that the three-point line should be situated between these distances for the participants of this study. 
In conclusion, the present study provides evidence of the effect of two three-point line designs on variables that are directly related to the shot, an area in which there is a lack of information. The results demonstrate that when the girls play with the three-point line delimited by the free throw lane, there in an increase in the frequency of ball possessions in which these players: (a) finish with a shot attempt, (b) shoot from inside the free throw lane and from a distance of between 4 and 5.65 meters, (c) attempt a standard or hook shot, and (d) attempt and score a three-point shot. This study confirms the necessity of consulting with analysts before introducing and modifying a rule in sport (Weidner, 1998; Nevill et al., 2008). Administrators of youth sport have little data for designing competitions and adapting them to game regulations (Weidner, 1998; Bergeron, 2007). The present study provides useful information as an example of analysis of the regulation modification before its definitive inclusion in athletic competition, especially in youth sport. These results may serve as the basis for studies that analyze physiological and psychological variables as well as variables related to the learning and motor development of the children that play minibasketball in real game-like situations.

\section{REFERENCES}

ADAMS, K.R. (1991). An evaluation of the three-point shot and selected variables on the point differential in basketball. Unpublished Master's thesis. Provo: Brigham Young University.

ANDREASEN, W.G. (1990). The effect of the three-point rule change in college basketball. Unpublished Master's thesis. Provo: Brigham Young University.

ANGUERA, M.T. (2003). La observación. [Observation]. In C. Moreno (Ed.), Evaluación psicológica. Concepto, proceso y aplicación en las áreas del desarrollo y de la inteligencia (271-308). Madrid: Sanz y Torres.

ANGUERA, M.T. \& BLANCO, A. (2003). Registro y codificación en el comportamiento deportivo. [Register and coding in athletic behaviour]. In A. Hernández (Coord.), Psicología del Deporte. Metodología (6-34). Buenos Aires: Efdeportes.

ARIAS, J.L.; ARGUDO, F.M. \& ALONSO, J.I. (2008). Three-point line's inclusion in minibasketball. International Journal of Sport Science, 4(13): 54-68.

ARIAS, J.L.; ARGUDO, F.M. \& ALONSO, J.I. (2009). Effect of the three-point line change on the game dynamics in girls' mini-basketball. Research Quarterly for Exercise and Sport, 80(3): 502-509.

BANDURA, A. (1977). Self efficacy: toward a unifying theory of behavioural change. Psychological Review, 84: 191-215.

BERGERON, M.F. (2007). Improving health through youth sports: is participation enough? New Directions for Youth Development, 115: 27-41.

BROWN, E.; WISNER, D. \& KONTOS, A. (2000). Comparison of the incidences of selected events performed by youth players in regulation and modified soccer games. International Journal of Applied Sport Sciences, 12: 2-21.

CASTELlAnO, J.; PEREA, A. \& HERNÁNDEZ, A. (2008). Analysis of the evolution of soccer at the world championships. Psicothema, 20(4): 928-932. 
CHASE, M.A. (2001). Children's self-efficacy, motivational intentions, and attributions in physical education and sport. Research Quarterly for Exercise and Sport, 72(1): 47-54.

CHASE, M.A.; EWING, M.E.; LIRGG, C.D. \& GEORGE, T.R. (1994). The effects of equipment modification on children's self-efficacy and basketball shooting performance. Research Quarterly for Exercise and Sport, 65(2): 159-168.

D'SILVA, L.; JOSEPH, S. \& KALLEY, R. (1988). Impact of three-point field goal areas rule on shooting in basketball. NIS Scientific Journal, 11(3): 25-32.

ELLIOTT, B. (1992). A kinematic comparison of the male and female two-point and threepoint jump shots in basketball. Australian Journal of Science and Medicine in Sport, 24(4): 111-117.

GOROSPE, G.; HERNÁNDEZ, A.; ANGUERA, M.T. \& MARTÍNEZ, R. (2005). Development and optimization of an observational tool for singles tennis. Psicothema, 17(1): 123-127.

HASSANDRA, M.; GOUDAS, M. \& CHRONI, S. (2003). Examining factors associated with intrinsic motivation in Physical Education: A qualitative approach. Psychology of Sport and Exercise, 4: 211-223.

IBÁÑEZ, S.J.; GARCÍA, J.; FEU, S.; PAREJO, I. \& CAÑADA, M. (2009). Shot efficacy in the NBA: a multifactorial analysis. Cultura, Ciencia y Deporte, 5(10): 39-47.

LIU, S. \& BURTON, A.W. (1999). Changes in basketball shooting patterns as a function of distance. Perceptual and Motor Skill, 89: 831-845.

MACPHAIL, A.; GORELY, T.; KIRK, D. \& KINCHIN, G. (2008). Children's experiences of fun and enjoyment during a season of sport education. Research Quarterly for Exercise and Sport, 79(3): 344-355.

MEMMERT, D. \& ROTH, K. (2007). The effects of non-specific and specific concepts on tactical creativity in team ball sports. Journal of Sports Sciences, 25(12): 1423-1432.

MEXAS, K.; TSITSKARIS, G.; KYRIAKOU, D. \& GAREFIS, A. (2005). Comparison of effectiveness of organized offences between two different championships in high level basketball. International Journal of Performance Analysis in Sport, 5(1): 72-82.

MILLER, S. \& BARTLETT, R. (1996). The relationship between basketball shooting kinematics, distance and playing position. Journal of Sports Sciences, 14: 243-253.

NEVILL, A.; ATKINSON, G. \& HUGHES, M. (2008). Twenty-five years of sport performance research in the Journal of Sports Sciences. Journal of Sports Sciences, 26(4): 413-426.

PALAO, J.M.; ORTEGA, E. \& OLMEDILLA, A. (2008). Technical and tactical preferences among basketball players in formative years. Iberian Congress on Basketball Research, 4: 38-41.

PARLEBAS, P. (2001). Juegos, deporte y sociedad. Léxico de praxiología motriz. [Games, sport and society. Dictionary of motor praxiology]. Barcelona: Paidotribo.

PELLETT, T.L. \& LOX, C.L. (1998). Tennis racket head-size comparisons and their effect on beginning collage players' achievement and self-efficacy. Journal of Teaching in Physical Education, 17: 453-467. 
PELLETT, T.L.; HENSCHEL-PELLETT, H.A. \& HARRISON, J.M. (1994). Influence of ball weight on junior high-school girls' volleyball performance. Perceptual and Motor Skills, 78: 1379-1384.

PIÑAR, M.I. (2005). Incidencia del cambio de un conjunto de reglas de juego sobre algunas de las variables que determinan el proceso de formación de los jugadores de minibasket (9-11 años). [Effect of rule modifications on some of the variables that determine the formative process of mini-basketball players (9-11 year olds)]. Granada: University of Granada.

PIÑAR, M.I.; ALARCÓN, F.; PALAO, J.M.; VEGAS, A.; MIRANDA, M.T. \& CÁRDENAS, D. (2003). Análisis del lanzamiento en el baloncesto de iniciación. [Shot analysis in youth basketball]. In A. Oña, \& A. Bilbao (Eds.), Actas del II Congreso Mundial de Ciencias de la Actividad Física y el Deporte. Deporte y Calidad de Vida (202-208). Granada: A. Oña, \& A. Bilbao.

PIÑAR, M.I.; ALARCÓN, F.; VEGAS, A.; CARREÑO, F. \& RODRÍGUEZ, D. (2002). Posiciones y distancias de lanzamiento durante la competición en minibasket. [Positions and shot distances during competition in mini-basketball]. In A. Díaz, P.L. Rodríguez, \& J.A. Moreno (Coords.), Actas del III Congreso Internacional de Educación Física e Interculturalidad (127-133). Murcia: Consejería de Educación y Cultura de la Región de Murcia.

PRUSAK, K. (1997). Meeting core requirements through efficient time management. Journal of Physical Education, Recreation \& Dance, 68(9): 9-10.

PRUSAK, K. \& DARST, P.W. (2000). Teaching strategies and game modifications to promote maximum participation in middle school physical education. Teaching Elementary Physical Education, 11(3): 18-23.

RINK, J.E. (1993). Teaching physical education for learning. St. Louis, MO: Mosby.

ROJAS, F.J.; CEPERO, M.; OÑA, A. \& GUTIÉRREZ, M. (2000). Kinematics adjustments in the basketball jump shot against an opponent. Ergonomics, 43: 1651-1660.

ROMANOWICH, P.; BOURRET, J. \& VOLLMER, T.R. (2007). Further analysis of the matching law to describe two- and three-point shot allocation by professional basketball players. Journal of Applied Behaviour Analysis, 40(2): 311-315.

TAVARES, F. \& GOMES, N. (2003). The offensive process in basketball - a study in high performance junior teams. International Journal of Performance Analysis in Sport, 3(1): 34-39.

TSITSKARIS, G.; THEOHAROPOULOS, A.; GALANIS, D. \& NIKOPOULOU, M. (2002). Types of shots used at the Greek national basketball championships according to the division and position of players. Journal of Human Movement Studies, 42: 43-52.

VOLLMER, T.R. \& BOURRET, J. (2000). An application of the matching law to evaluate the allocation of two- and three-point shots by college basketball players. Journal of Applied Behaviour Analysis, 33(2): 137-150.

WEIDNER, J.A. (1998). The effects of a modified ball in developing the volleyball pass and set for high-school students. Unpublished doctoral dissertation. Dekalb: Northern Illinois University. 
WEISS, M.R. \& WILLIAMS, L. (2004). The why of youth sport involvement: a developmental perspective on motivational processes. In M.R. Weiss (Ed.), Developmental sport and exercise psychology: A lifespan perspective (223-268). Morgantown, WV: Fitness Information Technology.

XIANG, P.; MCBRIDE, R. \& GUAN, J. (2004). Children's motivation in elementary Physical Education: a longitudinal study. Research Quarterly for Exercise and Sport, 75(1): 71-80.

Dr. José L. Arias: Department of Physical Education, Sport and Human Movement, Autonomous University of Madrid, Madrid, Spain. Tel.: 0034630157 246. E-mail: jlae84@ hotmail.com

(Subject editor: Prof. A.E. Pienaar) 